\title{
On the information value of (un)embedded network ties
}

Citation for published version (APA):

Hagedoorn, J., Letterie, W. A., \& Palm, F. C. (2007). On the information value of (un)embedded network ties. METEOR, Maastricht University School of Business and Economics. METEOR Research Memorandum No. 004 https://doi.org/10.26481/umamet.2007004

Document status and date:

Published: 01/01/2007

DOI:

10.26481/umamet.2007004

Document Version:

Publisher's PDF, also known as Version of record

\section{Please check the document version of this publication:}

- A submitted manuscript is the version of the article upon submission and before peer-review. There can be important differences between the submitted version and the official published version of record.

People interested in the research are advised to contact the author for the final version of the publication, or visit the DOI to the publisher's website.

- The final author version and the galley proof are versions of the publication after peer review.

- The final published version features the final layout of the paper including the volume, issue and page numbers.

Link to publication

\footnotetext{
General rights rights.

- You may freely distribute the URL identifying the publication in the public portal. please follow below link for the End User Agreement:

www.umlib.nl/taverne-license

Take down policy

If you believe that this document breaches copyright please contact us at:

repository@maastrichtuniversity.nl

providing details and we will investigate your claim.
}

Copyright and moral rights for the publications made accessible in the public portal are retained by the authors and/or other copyright owners and it is a condition of accessing publications that users recognise and abide by the legal requirements associated with these

- Users may download and print one copy of any publication from the public portal for the purpose of private study or research.

- You may not further distribute the material or use it for any profit-making activity or commercial gain

If the publication is distributed under the terms of Article $25 \mathrm{fa}$ of the Dutch Copyright Act, indicated by the "Taverne" license above, 
John Hagedoorn, Wilko Letterie, Franz Palm

On the information value of (un)embedded network ties

$\mathrm{RM} / 07 / 004$

JEL code : C11, D83, L20

\section{METE@R}

Maastricht research school of Economics

of TEchnology and ORganizations

Universiteit Maastricht

Faculty of Economics and Business Administration P.O. Box 616

NL - 6200 MD Maastricht

phone : :++31433883830

fax $\quad$ : ++31433884873 



\title{
ON THE INFORMATION VALUE
}

\section{OF (UN)EMBEDDED NETWORK TIES}

\author{
John Hagedoorn* \\ Wilko Letterie* \\ Franz Palm**
}

January 22, 2007

*Department of Organization and Strategy

**Department of Quantitative Economics Faculty of Economics and Business Administration Maastricht University

P.O. Box 616

6200 MD Maastricht

The Netherlands

Tel: (31) 43-3883823

Fax: (31) 43-3884893

E-mail: j.hagedoorn@os.unimaas.nl

w.letterie@os.unimaas.nl

f.palm@ke.unimaas.nl 


\title{
ON THE INFORMATION VALUE \\ OF (UN)EMBEDDED NETWORK TIES
}

\begin{abstract}
A firm sets up a network of information generating alliances to reduce technological uncertainty. This alliance group creates both advantages associated with similarity of existing partners and limitations due to restricted choice of new partners. Our model analyses the conditions (technological uncertainty, information overlap, alliance search costs, and the number of previous alliances) under which a firm opts for an embedded tie within an existing network or an unembedded tie with a new partner. (74 words)
\end{abstract}


The main question that this paper intends to answer is: under which conditions will a firm engage in alliances (network ties) with other companies to reduce the technological uncertainty in its environment and to gain access to useful technological information from its partners. It can choose to either increase collaboration within an already well-established network or to set up new alliances outside its existing network. In addition, we address the related issue of the optimal number of alliances that a firm might set up in a new network, given its alliance activity in an already existing network of alliances. We define alliances as inter-organizational entities that imply the sharing of resources and assets by two firms. In the context of the current paper, alliances are set up for joint technology development and joint technology scanning (Anand \& Khanna, 2000; Contractor and Lorange, 2000; Dussauge \& Garrette, 1999; Gulati, 1995; Hagedoorn, 1993). When a firm is engaged in more than one alliance with more than one other firm, its alliances are seen as multiple network ties in the context of an alliance group. Alliances that are part of a cohesive and dense network, where firms collaborate with each other over an extended period of time and through multiple alliances, are considered embedded ties from the perspective of the alliance group of the focal firm. Unembedded ties are those ties that refer to new alliances that a firm can set up with new partners outside its existing network or alliance group.

The current theoretical contribution provides a formal understanding of the strategic implications for the firm whether it engages in network ties within an already well-known alliance environment or whether it opts for a more experimental strategy with new alliances outside its existing network of alliances. Our paper also connects this formal theory to a body of management literature that can best be described as applied social network analysis that has enriched our understanding of the actual behavior of alliance-partners under both different network settings and changing conditions of technological development. This latter aspect of the environment in which a firm operates, i.e. the technological options that it faces, is theorized in the context of a 
technological paradigm and the technological trajectories that shape the direction of technological development.

In the next section, we outline the basic model that describes the technological uncertainty surrounding a firm, the cost of this uncertainty, and the optimization problem that a firm faces in the context of a network of alliances. This is followed by a section in which we discuss the value of the technological information that a firm gathers through alliances that can be characterized as embedded ties. It describes the benefits and limitations of embedded network ties, given the degree to which there is information overlap between a firm and its partners. The next section looks at the possible benefits of setting up an alliance outside an existing alliance group vis-à-vis the benefits of remaining within an existing network of alliances. This is followed by a comparison of the implications of an additional alliance in an existing network with a new and unembedded network tie, given the degree of technological uncertainty and information overlap with partners. The final element in our modeling of the information value of network ties refers to the optimal number of new ties that a firm could establish outside its existing network, given the cost of alliance formation, the technological uncertainty it faces, and the information value of alternative ties. Our key findings and main implications are presented in the discussion and conclusions, where we also discuss some interesting options for future work in terms of possible extensions to our model.

\section{THE BASIC MODEL}

We understand technological development to be intrinsically uncertain. This uncertainty is caused by the wide range of technological sources available to firms, the different patterns of diffusion and adoption of particular technological options, and the unstable preferences of consumers and companies (Nelson \& Winter, 1982; Rosenberg, 1996). A firm confronted with this technological uncertainty has some notion of the expected direction of technology and degree of uncertainty surrounding technological development. In that context, one has to think of a firm operating in a 
technological space, a set of industry-specific technological opportunities which are defined by a technological paradigm (Dosi, 1982). Somewhat similar to Kuhn’s understanding of scientific paradigms (Kuhn, 1977), this technological paradigm generates a broad search model for selected technological problems with which firms are confronted and that provides prescriptions for which directions of technological development to pursue and which to neglect (Dosi, 1982). Within a technological paradigm, rules that build both negative and positive heuristics stimulate search in certain directions. Technological paradigms are also characterized by exclusion effects as they are focused on certain technological possibilities that are identified by a technological community, in this context the firms that operate in the same technological space. Hence, technological paradigms refer to basic bodies of rules that guide the process of search within technologically mediated knowledge, that provide tools for puzzle solving in an otherwise uncertain technological environment.

Based on the overall heuristics given by a technological paradigm, firms will steer their search process towards an optimal future technology along technological trajectories (Dosi, 1982; Geels, 2002; Nelson \& Winter, 1982). These technological trajectories are based on technological imperatives (Rosenberg, 1976) that indicate the cumulative and self-generating nature of technology, based on normal problem solving activities within an existing technological paradigm, that drive technology into particular directions (Breschi, Malerba \& Orsenigo, 2000). The cumulative nature of these technological trajectories and the set of search procedures are common to a technological community or a set of firms that operate within the same technological paradigm. As a consequence an individual firm has some understanding of the direction of technological development and the heuristics and search procedures for new technologies.

In line with the above, we assume that the firm's optimal future technology is reflected by a parameter $T$. Using information that is already available the firm determines prior expectations about the variable $T$. The precise value of this parameter is unknown, uncertain and not controlled 
by the firm. The uncertainty surrounding the technology $T$ or the lack of knowledge of the technology $T$ is reflected by the prior distribution of $T$, which is normal with mean $\mu$ and variance $\sigma_{T}^{2}$

(1) $T \sim N\left(\mu, \sigma_{T}^{2}\right)$.

The technological direction ultimately chosen by the firm is given by the decision parameter $d$, where it is costly to implement a technology $d$ that does not match $T$. We assume that the costs, when choosing $d$, are given by ${ }^{1}$

(2) $\quad C(T, d)=a|T-d|, a>0$.

This specification implies that the costs are influenced by the extent to which the technology $d$ chosen by the firm fits with the unknown optimal technology represented by the parameter $T$. The firm minimizes the expected value of $C(T, d)$ by choosing $d^{\text {opt }}$. This means that $d^{\text {opt }}$ is determined by

(3) $\min _{d} \underset{T}{E} C(T, d)$,

where $E$ denotes the expectations operator with respect to $T$. If $T$ were known with certainty, it is obviously optimal to select $d=T$. However, $T$ is assumed to be unknown and uncertain, as discussed in the above. The minimized expected cost that the firm incurs equals $C$. We first need to determine the firm's optimal direction $d^{\text {opt }}$ using equations (2) and (3). We find that

$$
\min _{d} \underset{T, n}{E} C(T, d)=a \min _{d} \underset{T, n}{E}|T-d|
$$

The $n$ under the expectations operator denotes that $d$ is chosen, using the posterior distribution of $T$ after obtaining observations from its environment indicated by $n$. We assume that the observations 
obtained by the focal firm are jointly normally distributed with mean $T$ and a particular covariance structure that we depict in later sections. Then the posterior distribution of $T$ is normal with mean $\mu_{n}$ and variance $\sigma_{n}^{2}$ and therefore it is symmetrically distributed around its mean. ${ }^{2}$ As a consequence, the optimal strategy of the firm is given by $d^{o p t}=\mu_{n}$, i.e. the expected value of $T$, given its posterior distribution. The minimized value of equation (4) is given by (DeGroot, 1970: 233)

(5) $\quad \min _{d} \underset{T, n}{E} C(T, d)=a \sqrt{\frac{2 \sigma_{n}^{2}}{\pi}}=b \cdot \sigma_{n}$.

In this equation parameter $b$ collects terms which are constant. Equation (5) indicates that the expected cost that the firm incurs depends on the degree of uncertainty as given by $\sigma_{n}$ which remains after observations are obtained from its environment. The cost of collecting information about implementing a technology is an increasing function of the uncertainty as measured by $\sigma_{n}$. As a consequence, the firm is inclined to reduce the uncertainty it faces.

As already well established in the alliance literature (Contractor \& Lorange, 2002; Dussauge \& Garette, 1999; Gomes-Casseres, 1996; Hagedoorn, 1993; Stuart \& Podolny, 1996; Walker, Kogut \& Shan, 1997), a firm can set up a network of alliances geared towards joint technology development with its partners to reduce technological uncertainty. Using equation (5) the firm's optimization problem becomes to choose the network of alliances yielding the lowest value for

$$
T C=b \cdot \sigma_{n}+c_{n},
$$

where $c_{n}$ denotes the cost of building its network indicated by $n$. 


\section{INFORMATION FROM EMBEDDED TIES}

A firm does not need to fix $d$, the decision parameter for the technological direction that it chooses, immediately. As mentioned in the above, it has the opportunity to collect information about the properties of $T$ by forming alliances with other firms. When a firm uses alliances to jointly explore technologies with more than one partner, it engages in a network with a multitude of partners or an alliance group of companies that are linked to each other through alliances. In social network terminology this is referred to as an extended, n-step ego-network. The more a firm and its partners are connected to each other, the more this alliance group generates a densely connected network of firms. Such a group of partnering firms that share alliances are characterized by a much denser network of ties within that group compared to the relatively sparse or non-existing ties outside that group (Wasserman \& Faust, 1994). A dense network of alliance partners is also characterized by repeated interaction amongst group members during a more extended period of time (Gulati, 1998; Nohria \& Garcia-Pont, 1991).

Based on experience through previous contacts within a particular group of partners, a firm is expected to select partners for new alliances within this existing network (Gulati, 1998; Gulati \& Gargiulo, 1999). This repeated tie effect creates strong cohesive ties through frequent interaction in a network of cooperating firms (Gomes-Casseres, 1996; Harrigan, 1985; Nohria \& Garcia-Pont, 1991). When a firm invests a substantial amount of time, assets, technology, and human resources to establish these strong relationships, changing partners in the short run is not very likely due to switching costs and the reputation effect that this might have on other existing relationships with its partners (Chung, Singh \& Lee, 2000). Therefore, a firm is expected to prefer local search, i.e. it rather replicates its existing ties than search for new partners outside its existing network of partners (Anand \& Khanna, 2000; Dyer \& Singh, 1998; Gulati, 1998; Kale \& Singh, 1999; Walker et al., 1997). In the context of (joint) technological development and the sharing of technological information, a firm uses local search to start common R\&D projects based on technological 
characteristics that it shares with its partners (Stuart \& Podolny, 1996). An explanation for the relevance of this overlap or similarity in $R \& D$ activities for the local search for partners is found in the need to assimilate and understand the technology that a firm develops and shares with its partners (Lane \& Lubatkin, 1998; Mowery, Oxley \& Silverman, 1996; Rosenkopf \& Nerkar, 2001). This similarity encourages further interaction between firms as similarity, interaction and mutual attraction reinforce each other (Brass, Butterfield \& Skaggs, 1998). In this context of local search and similarity, firms maintain and replicate strong and multiple ties with each other, which lead to the formation of densely connected alliance networks (Gomes-Casseres, 1996). As these group members focus on similar technologies, local search for partners within this network contributes to the technological competence and information sharing of cooperating group members in their particular technological paradigm (Rosenkopf \& Nerkar, 2001).

Each time the firm forms an alliance with a firm from the current network it is connected to, i.e. alliance group A, it obtains an observation $x_{i}$. We assume that the expected value of $x_{i}$ equals $T$. Hence, if the firm obtains an observation $x_{i}$ this yields some information about the desired future direction of the technology. We also assume that $x_{i}$ is normally distributed and that its variance is given by $\sigma_{x}^{2}$ and that two observations $x_{i}$ and $x_{j}$ (where $i \neq j$ ) are positively correlated which is represented by a correlation coefficient $\rho \geq 0$. This means that knowledge obtained from these partners partly overlaps. Hence, to a certain extent observations from these partners are similar. If the firm has established $m$ alliances within an existing network of partners, that we refer to as alliance group A, this yields $m$ observations $x_{1}, x_{2}, \ldots, x_{m}$. The covariance matrix $\Sigma_{x}^{m A}$ for these observations is 
(7) $\quad \Sigma_{x}^{m A}=\left[\begin{array}{cccc}\sigma_{x}^{2} & \rho \sigma_{x}^{2} & \cdot & \rho \sigma_{x}^{2} \\ \rho \sigma_{x}^{2} & \sigma_{x}^{2} & \cdot & \cdot \\ \cdot & \cdot & \cdot & \rho \sigma_{x}^{2} \\ \rho \sigma_{x}^{2} & \cdot & \rho \sigma_{x}^{2} & \sigma_{x}^{2}\end{array}\right]$.

The variance of $T$ given its posterior distribution which incorporates all information $x_{1}, x_{2}, \ldots, x_{m}$ obtained from alliance group $\mathrm{A}$ is given by

$$
\sigma_{m A}^{2}=\left(\frac{m}{\sigma_{x}^{2}(1-\rho)+m \rho \sigma_{x}^{2}}+\frac{1}{\sigma_{T}^{2}}\right)^{-1} .
$$

The derivation of this expression is provided in the appendix. From this equation we can see that if the number of ties in alliance group A becomes very large, uncertainty reduction becomes very difficult as $\rho>0$. In particular,

(9) $\lim _{m \rightarrow \infty} \sigma_{m A}^{2}=\left(\frac{1}{\rho \sigma_{x}^{2}}+\frac{1}{\sigma_{T}^{2}}\right)^{-1}$.

This indicates that if no information overlap exists (i.e. $\rho=0$ ), then uncertainty about $T$ could be countered entirely by engaging in a large number of alliances. In fact, equation (9) shows the variance $\sigma_{m A}^{2}$ becomes zero if the number of alliances $m$ is very large in case $\rho=0$. However, if a certain degree of information overlap exists (i.e. $\rho>0$ ) then it is impossible to completely obtain certainty concerning the parameter $T$.

\section{INFORMATION FROM UNEMBEDDED TIES}

We expect that the participation of a firm in a particular network of alliances creates the highest returns in terms of technology observations at the early stages of that alliance group formation. The new network environment and the growing abundance of both direct and indirect ties increase 
the probability that the firm will discover and exploit new technological opportunities. However, gradually the benefits of being a group member or network participant will level off when firms begin to experience the consequences of over-embeddedness (Burt, 1992; Gargiulo \& Benassi, 2000; Hagedoorn, 2006; Uzzi, 1997).

The positive effect of an alliance network membership, as described in the above, is based on the replication of preferential relations within a network of partners. However, this positive effect can turn into a paralyzing effect when a firm becomes locked-in within its alliance group. The literature refers to this as relational inertia which occurs when group members are constrained in their partner choice which prohibits them from linking up with firms from another alliance group or other outside partners (Gomes-Casseres, 1996). In that context a firm may even experience implicit or explicit social pressure from its partners to replicate its ties within its alliance group to prevent knowledge leakage to firms outside of the existing alliance network (Duysters, Hagedoorn \& Lemmens, 2003). Such an expectation of loyalty to other current network partners can prevent a firm from setting up alliances with firms from other alliance groups as this can create a conflict of interest with its existing network of partners (Gulati, Nohria \& Zaheer, 2000; Nohria \& Garcia-Pont, 1991). Competing alliance networks can thus block alternative partnering opportunities for a firm with non-group members (Gomes-Casseres, 1996). As a consequence, potential partners outside alliance groups are excluded from partner selection. Based on its initial preferences and choices, a firm can become locked-in within its alliance group, where it engages only in local search for partners and it gradually becomes over-embedded in its existing network.

The embeddedness within an alliance group and the recurring repeated ties within this alliance group can also lead to increasing technological similarity of partners that engage in extended technology cooperation. The technological profiles of firms are expected to gradually converge as they share the same research agenda. In the long run this will decrease potential 
learning effects among alliance partners (Chung et al., 2000; Duysters et al, 2003; Mowery et al., 1996; Saxton, 1997) as too much focus on local search with the same group of partners can lead firms to develop technological inflexibility (Leonard-Barton, 1995). This technological inflexibility among network members will increase the likelihood that they begin to suffer from the effect of being cognitively locked-in (Uzzi, 1997; Gargiulo \& Benassi, 2000). This effect isolates alliance group members from firms outside of a network, as it filters the observations, the information and the new perspectives that could otherwise reach group members. In such a state of an inflexible and technologically over-embedded network (Uzzi, 1997) an embedded firm faces decreasing opportunities for learning, useful information sharing, and innovation. As indicated by Foster (1986) group pressure in embedded networks can even lead members to increase their efforts in existing technologies rather than to explore new technological trajectories. As a consequence, a firm within an over-embedded alliance group will gradually become very restrained in its observations regarding new technological opportunities.

In the remainder of this section we develop a model to address the question under which conditions it is either optimal for a firm to stay exclusively within a certain alliance group or to also link up with other firms outside its alliance group. In that context, it follows in a straightforward manner that the posterior variance of the parameter $T$ after $m+1$ observations from other firms belonging to a firm’s alliance group A, becomes

$$
\sigma_{(m+1) A}^{2}=\left(\frac{m+1}{\sigma_{x}^{2}(1+m \rho)}+\frac{1}{\sigma_{T}^{2}}\right)^{-1} .
$$

We assume that if the firm builds an alliance with a firm from network $B$, that the information obtained from this alliance does not show overlap with observations derived from its existing alliance group, i.e. network A. Also, from the perspective of network A, this additional tie from network B is to be considered as a non-embedded tie as this new alliance is not built on the 
existing ties within the firm's existing alliance group A. In statistical terms this means that this observation is uncorrelated with the observations obtained previously from alliances in alliance group A. An alliance with a firm from network B yields an observation $y$, which is normally distributed with mean $T$ and variance $\sigma_{y}^{2}$. Hence, if the firm establishes alliances with $m$ firms from its existing alliance group A and one alliance with a firm from network B, indicated by its new alliance group $m A+1 B$, the covariance matrix of the observations is given by

$$
\sum_{x, y}^{m A+1 B}=\left(\begin{array}{ccccc}
\sigma_{x}^{2} & \rho \sigma_{x}^{2} & \cdot & \rho \sigma_{x}^{2} & 0 \\
\rho \sigma_{x}^{2} & \cdot & \cdot & \cdot & \cdot \\
\cdot & \cdot & \cdot & \rho \sigma_{x}^{2} & 0 \\
\rho \sigma_{x}^{2} & \cdot & \rho \sigma_{x}^{2} & \sigma_{x}^{2} & 0 \\
0 & \cdot & 0 & 0 & \sigma_{y}^{2}
\end{array}\right) .
$$

It follows straightforwardly that the variance of the parameter $T$ after establishing network $m A+$ $1 B$ is equal to

$$
\sigma_{m A+1 B}^{2}=\left(\frac{m}{\sigma_{x}^{2}(1+(m-1) \rho)}+\frac{1}{\sigma_{T}^{2}}+\frac{1}{\sigma_{y}^{2}}\right)^{-1}
$$

Suppose now that a network consists of $m$ firms of type A. The expected net change of the loss due to adding one alliance of type A equals $L_{A \mid m A}=b \cdot \sigma_{(m+1) A}-b \cdot \sigma_{m A}+c_{A \mid m A}$ where $c_{A \mid m A}$ denotes the marginal cost to be made when expanding the network of size $m$ by one alliance with a type A firm. Marginal costs have to be distinguished from total costs $c_{m A+l B}$ for setting up a network consisting of $m$ alliances of type A firms and 1 alliance with a type B firm. This expansion of the network is sensible if $L_{A \mid m A}<0$. If $L_{A \mid m A}=0$, then the network has reached the optimal number of type A firms. The expected net change of the loss function as a result from adding a type B firm to the network consisting of $m$ type A firms equals 
$L_{B \mid m A}=b \cdot \sigma_{m A+1 B}-b \cdot \sigma_{m A}+c_{B \mid m A}$ where $c_{B \mid m A}$ denotes the marginal cost of adding a type B firm to the network of $m$ type A firms. The expected benefit from the expansion of the network is determined by the reduction of uncertainty, measured by the change in the posterior variance. When $L_{A \mid m A}<0$ and $L_{B \mid m A}<0$, the decision to add a type A firm and the decision to expand the network with a type B firm (or equivalently to set up a new network with one type B firm) are both sensible. Adding a type B firm to the network rather than a type A firm may be desirable even when $L_{A \mid m A}<0$, if $L_{B \mid m A}<0$ and $L_{B \mid m A}<L_{A \mid m A}$. The latter condition holds if $b \cdot \sigma_{m A+1 B}-b \cdot \sigma_{m A}+c_{B \mid m A}<b \cdot \sigma_{(m+1) A}-b \cdot \sigma_{m A}+c_{A \mid m A}$. Hence, to assess whether $m$ observations from alliance network $A$ and one observation based on an unembedded tie from alliance network B are more desirable than $m+1$ observations from embedded ties in network $\mathrm{A}$, the firm should calculate

$$
L=b \cdot\left(\sigma_{m A+1 B}-\sigma_{(m+1) A}\right)+c_{B \mid m A}-c_{A \mid m A},
$$

where $L$ compares, on the one hand, the features of information obtained from the two different networks, as given by $\sigma_{(m+1) A}$ and $\sigma_{m A+1 B}$, whereas, on the other hand, the focal firm evaluates the costs associated with these different alliance groups. These costs are given by $c_{B \mid m A}$ and $c_{A \mid m A}$. It is optimal to switch to a partner from network B if $L<0$. In that case the net value of information obtained from a partner that belongs to the new network B is higher than the value associated with information obtained from its original alliance group A.

We assume that $c_{B \mid m A}>c_{A \mid m A}$ for two main reasons. First, as explained in the previous section, it is likely that building up an additional alliance with a firm that is already well connected within an existing alliance group involves relatively low search costs. Also, through referral, other partners may hint at valuable alliance contacts within the alliance group. Second, as already explained in the early part of the current section, by turning to a new partner that belongs to 
another network or alliance group (here B) the focal firm may compromise its alliances with firms from its existing alliance group A. Such alliances may have been set up under the assumption that a firm will not turn to other firms to avoid valuable information leaks to firms that may harm the competitive position of firms in network A. Given the already substantial costs of alliances (Gulati, 1995; Kale \& Singh, 1999), maintaining these existing alliances, while also engaging in an alternative alliance, will ask additional managerial effort from the focal firm to maintain or rebuild trust (Mesquita, 2007). Hence, these efforts will create additional costs for the firm in order to continue its relationships with its ‘older’ partners (Gomes-Casseres, 1996; Parkhe, 1993).

Our interpretation of the model refers to the case that once a firm forms an alliance with a firm from network B, it is likely to break up with its former alliance group A for two reasons. First, as argued in the above, the earlier partners may feel betrayed if the focal firm is turning to alternative partners. Returning to partners from network A once an alliance has been formed with a firm from network B may be very difficult and hence costly to realize. In terms of our model, one could assume that the cost of returning to alliance group A is very high and that returning is impossible. Second, we actually analyze the behavior of a representative firm from network A. The constituents of this network all face similar opportunities. If one firm has an incentive to turn to partners from an alternative network B, then all firms from network A could be inclined to take the same decision. In that case, alliance group A becomes inherently unstable. However, we like to note that if the focal firm leaves network A when joining network B, it still keeps the information that it acquired with or from its previous partners. Strictly speaking there is no gain to be expected from returning to network $\mathrm{A}$ as the information provided by the alliance group $\mathrm{A}$ in the past has already been incorporated in the posterior variance of the technology parameter $T$. 


\section{COMPARING AN ADDITIONAL EMBEDDED TIE WITH AN UNEMBEDDED TIE}

In the previous section we observed that it is likely that the costs of establishing an alliance with a firm from network B are higher than the costs of forming an additional tie with a firm from the current alliance group: $c_{B \mid m A}>c_{A \mid m A}$. Due to this, our model indicates that from an informational point of view 'leaving' alliance network A as the exclusive alliance group for the firm becomes a possibility only if the information from network B yields a more precise estimate of the desired future technology than an observation from a new partner in alliance group A: $\sigma_{(m+1) A}>\sigma_{m A+1 B}$. This is the case if

$$
\sigma_{y}^{2}<\sigma_{x}^{2} \frac{(1+m \rho)(1+(m-1) \rho)}{1-\rho}
$$

Hence, if the variance of an observation derived from network B is not too high, it may be optimal to set up an alliance with a new partner from network B instead of an additional alliance in group A. In fact, the condition in equation (14) may even be satisfied if information obtained from network B contains more noise than information received from a firm belonging to network A (i.e. $\sigma_{y}^{2}>\sigma_{x}^{2}$ ) because $\sigma_{x}^{2}<\sigma_{x}^{2} \frac{(1+m \rho)(1+(m-1) \rho)}{1-\rho}$. This feature of the model reflects that an alliance with a firm from network B yields information that does not overlap with information obtained previously from firms in network A. Due to this, the estimate of the parameter $T$ may become more precise by allying with a network B firm than with a network A firm (i.e. $\sigma_{m A+1 B}<$ $\left.\sigma_{(m+1) A}\right)$ even if $\sigma_{y}^{2}>\sigma_{x}^{2}$.

We also find that with higher uncertainty it is probably desirable to select a partner from network B and to start operating outside alliance group A since 
(15) $\frac{\partial L}{\partial \sigma_{T}^{2}}=\frac{b}{2 \sigma_{T}^{4}}\left(\sigma_{m A+1 B}^{3}-\sigma_{(m+1) A}^{3}\right)<0$.

With lower levels of technological uncertainty, when a firm has a clear perspective on the relevant technological trajectory, based on the observations made from within its alliance group, there is little need to engage in new alliances with firms outside its network (Rowley, Behrens \& Krackhardt, 2000). However, with increasing levels of technological uncertainty, when a firm is confronted with an increasing number of alternative technological trajectories (Bower \& Christensen, 1995; Burgelman \& Grove, 1996; Tushman \& O'Reilly, 1996), new partners outside a firm’s existing alliance group might create better opportunities than those provided by repeated ties with an extant network of partners. As such this may have a negative effect on the attractiveness of alliances in an existing network, which can lead towards a more outward orientation in partner selection as a firm embedded in a network may look for new opportunities outside this existing network. This argument is reflected in Rowley et al. (2000), where it is argued that a high network density of ties with a small set of long-term partners is not positive for a firm operating in a technologically uncertain environment when it is interested in widening its technological options. This point also echoes the 'structural holes' argument made by Burt (1992) which we interpret in terms of the benefits for a firm that forms bridges among previously unconnected parts of the overall alliance network as it gains access to new and non-redundant information about new technological trajectories. Also, Park \& Ungson (1997) found that firms operating in dense networks within the US electronics industry were more inclined to enter into alliances with new partners, outside their existing network, which would offer new opportunities for their collaborative efforts.

Another issue that is likely to affect the choice for repeated ties and staying in a certain network or to engage in alternative alliances outside this group refers to the degree of technological information overlap between current group members (Mowery, Oxley \& Silverman, 
1998). To address this topic we determine how the firm's decision rule given by equation (13) is affected by the parameter $\rho$ in our model. It reflects the information similarity of the observations obtained from the partnerships due to overlap of for instance knowledge and technology amongst the firms in the network. We find after some straightforward but time-consuming derivations that ${ }^{3}$

$$
\frac{\partial L}{\partial \rho}=\frac{b m}{2 \sigma_{x}^{2}}\left(\frac{\sigma_{m A+1 B}^{3}(m-1)}{(1+(m-1) \rho)^{2}}-\frac{\sigma_{(m+1) A}^{3}(m+1)}{(1+m \rho)^{2}}\right)<0 .
$$

This expression indicates that if the observations obtained from alliance group A are highly correlated, it is more likely the focal firm will choose an observation from network B. This partly reflects the empirical findings by Mowery et al. (1998) which indicate that firms prefer repeated ties with previous partners with which they share a technological information overlap which then leads to an increased post-alliance overlap. However, if the technological information overlap of partners increases further, it has a curvilinear, inverted U-shaped, effect on future alliance formation between these firms.

\section{THE OPTIMAL NUMBER OF TIES}

In this section we discuss the optimal number of new ties the focal firm wishes to establish given that it has already formed alliances with firms from its alliance group $\mathrm{A} .{ }^{4}$ We assume that the number of alliances the focal firm wants to form with companies from network B is given by $u$. The optimal value for $u$ is found by solving

$$
C=\min _{u}\left(\min _{d} \underset{T, u}{E} C(T, d)+c_{u B \mid m A}\right)
$$


We assume here that $c_{u B \mid m A}$ denotes the cost of setting up alliances with $u$ firms from network B given that alliances were previously formed with firms from network A. Using equation (5) the firm’s optimization problem becomes

$$
\min _{u}\left(b \sigma_{m A+u B}+c_{u B \mid m A}\right) .
$$

According to this equation we first need to determine the posterior variance $\sigma_{m A+u B}^{2}$ resulting from $u$ observations obtained from alliances with firms in network B, given that $m$ ties were previously formed with firms from alliance group A. Each time the focal firm forms a tie with a new partner it receives an observation $y_{j}$ which is normally distributed with mean $T$ and variance $\sigma_{y}^{2}$. We assume that observations $x_{i}$ and $y_{j}$ are independently distributed. This means that the two different networks yield information concerning the technology parameter $T$ that does not overlap. However, within the two networks there is some degree of overlap. Hence, two observations $y_{j}$ and $y_{k}$ from alliance group B (with $j \neq k$ ) are correlated and the coefficient of correlation between these observations is given by $\rho^{*}$.

Suppose that after the focal firm has established $m$ ties with firms from network A, $u$ alliances are formed with companies that belong to network B. The $(m+u)$ by $(m+u)$ covariance matrix for these observations then equals

(19) $\quad \Sigma_{x, y}^{m A+u B}=\left(\begin{array}{cccccccc}\sigma_{x}^{2} & \rho \sigma_{x}^{2} & \cdot & \rho \sigma_{x}^{2} & 0 & \cdot & \cdot & 0 \\ \rho \sigma_{x}^{2} & \sigma_{x}^{2} & \cdot & \cdot & \cdot & \cdot & \cdot & \cdot \\ \cdot & \cdot & \cdot & \rho \sigma_{x}^{2} & \cdot & \cdot & \cdot & \cdot \\ \rho \sigma_{x}^{2} & \cdot & \rho \sigma_{x}^{2} & \sigma_{x}^{2} & 0 & \cdot & \cdot & 0 \\ 0 & \cdot & \cdot & 0 & \sigma_{y}^{2} & \rho^{*} \sigma_{y}^{2} & \cdot & \rho^{*} \sigma_{y}^{2} \\ \cdot & \cdot & \cdot & \cdot & \rho^{*} \sigma_{y}^{2} & \sigma_{y}^{2} & \cdot & \cdot \\ \cdot & \cdot & \cdot & \cdot & \cdot & \cdot & \cdot & \rho^{*} \sigma_{y}^{2} \\ 0 & \cdot & \cdot & 0 & \rho^{*} \sigma_{y}^{2} & \cdot & \rho^{*} \sigma_{y}^{2} & \sigma_{y}^{2}\end{array}\right)$. 
The posterior variance of $T$ given $m$ and $u$ observations respectively from both networks A and B is given $\mathrm{by}^{5}$

$$
\sigma_{m A+u B}^{2}=\left(\frac{m}{\sigma_{x}^{2}(1-\rho)+m \rho \sigma_{x}^{2}}+\frac{u}{\sigma_{y}^{2}\left(1-\rho^{*}\right)+u \rho^{*} \sigma_{y}^{2}}+\frac{1}{\sigma_{T}^{2}}\right)^{-1} .
$$

Let us now return to the optimization problem faced by the firm. First we define $Z=\frac{1}{\sigma_{m A+u B}^{2}}$. Next we observe that $c_{u B \mid m A}^{\prime}$ and $c_{u B \mid m A}^{\prime \prime}$ denote the first and second order derivative of $c_{u B \mid m A}$ with respect to $u$ respectively. We assume that $c_{u B \mid m A}^{\prime}>0$ and that $c_{u B \mid m A}^{\prime \prime} \geq 0$. The latter assumption is sufficient to ensure that the second order condition for optimality below is satisfied but it is not necessary. In the special case where marginal costs are constant, the solution to the optimization problem is optimal. The first and second order conditions for the optimization of equation (18) become

$$
\text { FOC: }-1 / 2 b Z^{-\frac{3}{2}} \cdot \frac{\left(1-\rho^{*}\right)}{\sigma_{y}^{2}\left(1-\rho^{*}+u \rho^{*}\right)^{2}}+c_{u B \mid m A}^{\prime}=0
$$

$$
\mathrm{SOC}: \quad \frac{3}{4} \frac{b Z^{-5 / 2}}{\sigma_{y}^{4}} \frac{\left(1-\rho^{*}\right)^{2}}{\left(1-\rho^{*}+u \rho^{*}\right)^{4}}+\frac{b Z^{-3 / 2}}{\sigma_{y}^{2}} \frac{\left(1-\rho^{*}\right)\left(1-\rho^{*}+u \rho^{*}\right) \rho^{*}}{\left(1-\rho^{*}+u \rho^{*}\right)^{4}}+c_{u B \mid m A}^{\prime \prime} \geq 0
$$

From the second order condition (SOC), we observe that the requirement for a minimum is satisfied since all elements are positive. The first order condition (FOC) implicitly characterizes the optimal number of alliances. It is not possible to obtain an explicit solution for the optimal value for the number of alliances in network B, i.e. $u$. In practice one will take an integer value resulting from the optimization problem in the above. However, in the appendix we derive a 
number of comparative static results that we depict in the following proposition and which are based on the notion that $u$ is a continuous variable. ${ }^{6}$

\section{Proposition:}

The optimal number of alliances with firms in network B, denoted by $u$, given that the firm has already established $m$ alliances with firms from network A,

- decreases with the marginal cost $c_{u B \mid m A}^{\prime}$ of setting up an alliance,

- $\quad$ increases with the cost attached to making mistakes as measured by the parameter $a{ }^{7}$

- increases with the degree of uncertainty the firm faces a priori as measured by $\sigma_{T}^{2}$,

- increases with the correlation coefficient $\rho$,

- increases with the variance $\sigma_{x}^{2}$,

- decreases with the number of alliances $m$ in network A.

According to the proposition in the above, the optimal number of alliances decreases with the marginal cost of forming an alliance (i.e. $c_{u B \mid m A}^{\prime}$ ). Also, if the cost associated with making mistakes in selecting the desirable future technology increases as measured in our model by the parameter $a$, the optimal number of ties $u$ increases. The focal firm is also willing to establish more alliances in case the level of prior uncertainty as measured by $\sigma_{T}^{2}$ is higher. This result indicates that a relationship exists between a firm's incentive to collect information and the level of technological uncertainty it faces in its environment. Various studies have observed that under higher technological uncertainty firms engage in large numbers of alliances to enhance their learning and to improve the ability to collect information (Gomes-Casseres, 1996; Powell, Koput \& SmithDoerr, 1996; Walker et al. 1997). The results regarding the parameters $\rho, \sigma_{x}^{2}$, and $m$ are highly related. They are due to the assumption that the focal firm already established a number of 
alliances in its alliance group A. These ties already provided information to reduce the uncertainty concerning the technology parameter $T$. The quality and amount of this information determines the incentive to collect additional information from network B. The quality of information is affected by the degree of information overlap in network A as given by the correlation coefficient $\rho$. The proposition indicates that if information is highly similar across the partners in network $\mathrm{A}$, then the number of alliances the focal firm is likely to form with firms in network B is high. Also, if the information obtained from firms in alliance group A is subject to substantial noise ( $\sigma_{x}^{2}$ is high), then it is desirable to establish a high number of ties with firms in network B. The final result depicted in the proposition refers to the amount of information obtained from network A. It indicates that if a large number of observations have been obtained from alliance group A ( $m$ is high), then there is no need to form many additional alliances with firms in network B. This result stems from the fact that technological uncertainty in our model is to some extent one dimensional. The firm only needs to learn about one single technological trajectory, reflected by the parameter $T$. Since firms from both networks A and B provide information on the same technology $T$, the amount of information obtained from network A affects the need for further information to be gained from network B.

\section{DISCUSSION AND CONCLUSIONS}

The model that we developed in the above generates a number of interesting stylized facts regarding the uncertainty of technology development, inter-firm alliances, information value of network ties and the level of embeddedness of these ties. As already indicated in the individual sections, these theoretical findings are relevant in the context of the management and organization literature on alliances and networks with some clear implications for the understanding of the particular choices that a firm makes when it sets up a new alliance. 
Given the uncertainty of the technological development surrounding firms, a firm operating in such an environment can use alliances, where it gathers information, undertakes joint R\&D, and develops new technologies with its partners, to reduce this technological uncertainty. By setting up multiple alliances a firm creates a network for which it is expected to choose an optimal configuration with the lowest possible cost for setting up this multiple partner network. When firms form alliances with the same group of partners during an extended period of time, they establish a cohesive network of alliances characterized by repeated ties, local search for partners, and shared technological resources that lead to technological information overlap and a significant degree of technological similarity of partners in this network of embedded ties. Under these conditions, it pays for an individual firm to reduce the technological uncertainty with which it is confronted by entering into an additional alliance through an embedded tie with a partner from this already well-embedded network. However, it may also be beneficial for a firm to enter into an alliance with a single partner outside its existing alliance group, if that partner yields more precise new information on the relevant technology than could be obtained from partners in its existing network.

Once a firm becomes embedded in its network, it faces two major limitations when it comes to choosing new partners. One limitation follows from the consequences of over-embeddedness. In that case, where cohesive networks of partners can gradually create lock-in effects through which a firm is restricted in choosing a new partner outside its alliance group due to peer pressure for continued local search based on group loyalty. In terms of our model this peer pressure could be reflected in higher costs of forming an alternative network with new partners. The other limitation follows from long-term technology cooperation within the same group of partners. Due to this long-term technology cooperation, the technological profiles of firms converge, learning opportunities from partners diminish and firms begin to suffer from some degree of technological 
inflexibility which will ultimately block their view on interesting new technological opportunities that may very well lie outside their existing alliance group.

Our model indicates that given relatively low search costs for additional alliances within an existing network of partners, a firm will 'ceteris paribus' prefer to enter into an additional alliance within its existing network. It is only worthwhile for a firm to establish an alliance with a partner outside its existing network when the value of the information regarding technological development, obtained through this 'outside' alliance, outweighs the cost advantage of finding an additional partner within its already existing network.

The level of technological uncertainty that a firm faces also has an impact on its preference for setting up either an alliance with a partner from its existing network or establishing an alliance with a new partner outside its existing network. Our model indicates that the higher the level of technological uncertainty in the environment of a firm, the more a firm should consider entering into an alliance with a new partner instead of forming an alliance with another firm from its existing alliance group. The degree to which partners in an existing network of alliances share an overlap in their technology, i.e. the degree to which technology observations gained through alliances are correlated, has a positive effect on the decision of a firm to enter into a new alliance with a partner outside its existing network.

The incentive to form alliances with firms in a new network is determined by a number of factors. The cost of forming a tie decreases the optimal number of alliances. However, if the cost of making an error in choosing the right technology is high then it is worth engaging in a large number of new alliances. Also, to counter a high level of technological uncertainty a firm is likely to form many alliances. The quality and amount of previous ties to firms affects a firm's incentive to engage in additional alliances. If the firm has previously formed ties with companies that are subject to information overlap then it is likely that many additional ties are desirable. Also if observations obtained already are featured by a high level of noise, i.e. they yield imprecise 
information, the focal firm is likely to establish more alliances in the future. Finally, if the focal firm has engaged in many alliances previously, it is likely that the need for additional alliances decreases.

A natural extension of the framework adopted in this paper could consist of allowing for an alternative technological trajectory with major changes over time. Technology could be assumed to be either shaped through $R \& D$ by firms in a particular network or to be truly exogenous to that network. In the latter case, firms within that network might have an additional incentive to form alliances with firms involved in developing the new technology. What matters then is the type and amount of information on the new technology that the focal firm receives from old and new partners and the costs at which this information is obtained. This extension goes beyond the scope of this paper and is left for future research.

It should be observed that this paper adopts a partial analysis by investigating the decisions of the focal firm and the uncertainties and the opportunities it faces. However, it is of importance to emphasize that when firms in a particular alliance group are very similar (which is assumed here) they also face related challenges. If one of these similar firms has an incentive to engage in a new network with new partners, all firms in the already existing network are likely to have this incentive as well. In such a situation, one would expect to see several (or all) firms to defect from the existing network and team up with firms from the new network. 


\section{REFERENCES}

Anand, B.N. \& Khanna, T. 2000. The structure of licensing contracts. Journal of Industrial Economics, 48: 103-135.

Baltagi, B. 1995. Econometric analysis of panel data. Chichester (UK): Wiley.

Bower, J.L. \&. Christensen, C.M. 1995. Disruptive technologies: Catching the wave. Harvard Business Review, January, 73 (1): 43-54

Brass, D.J., Butterfield, K.D. \& Skaggs, B.C. 1998. Relationships and unethical behavior: A social network perspective, Academy of Management Review, 23(1): 14-31.

Breschi, S., Malerba, F. \& Orsenigo, L. 2000. Technological regimes and Schumpeterian patterns of innovation. The Economic Journal, 110: 388-410.

Burgelman, R.A. \& Grove, S.A. 1996. Strategic dissonance. California Management Review, 38(2), 8-28.

Burt, R.S. 1992. Structural holes - The social structure of competition. Cambridge, MA: Harvard University Press.

Chung, S.A., Singh, H. \& Lee, K. 2000. Complementarity, status similarity and social capital as drivers of alliance formation. Strategic Management Journal, 21: 1-20

Contractor, F.J. \& Lorange, P. (eds.) 2002. Cooperative strategies and alliances. Oxford (UK): Elsevier.

DeGroot, M.H. 1970. Optimal statistical decisions. New York: McGraw-Hill Dosi, G. J. 1982. Technological paradigms and technological trajectories. Research Policy, 11: 147-162.

Dussauge, P.\& Garrette, B. 1999. Cooperative strategy: Competing successfully through strategic alliances. New York: Wiley.

Duysters, G., Hagedoorn, J. \& Lemmens, C. 2003. The effect of alliance block membership on innovative performance. Revue d'Economie Industrielle. 103: 59-70 
Dyer, J.H. \& Singh, H. 1998. The relational view: Cooperative strategy and sources of interorganizational competitive advantage. Academy of Management Review, 23: 660-679.

Foster, R.N. 1986. Innovation: The attacker’s advantage, New York: Summit Books.

Gargiulo, M. \& Benassi, M. 2000. Trapped in your own net? Network cohesion, structural holes and the adaptation of social capital. Organization Science, 11 (2): 183-196

Geels, F.W. 2002. Technological transition as evolutionary reconfiguration processes: A multilevel perspective and a case-study. Research Policy, 31: 1257-1274.

Gomes-Casseres, B. 1996. The alliance revolution: The new shape of business rivalry. Cambridge, MA: Harvard University Press

Gulati, R. 1995. Social structure and alliance formation patterns: A longitudinal analysis.

Administrative Science Quarterly. 40: 619-652

Gulati, R. 1998. Alliances and networks. Strategic Management Journal. 19: 293-317

Gulati, R.\& Gargiulo, M. 1999. Where do inter-organizational networks come from? American Journal of Sociology, 104: 1439-1493

Gulati, R., Nohria, N. \& Zaheer, A. 2000. Strategic networks. Strategic Management Journal, 21: $203-215$

Hagedoorn, J. 1993. Understanding the rationale of strategic technology partnering: Interorganizational modes of cooperation and sectoral differences. Strategic Management Journal, 14: 371-385

Hagedoorn, J. 2006. Understanding the cross-level embeddedness of interfirm partnership formation. Academy of Management Review 31: 670-680.

Harrigan, K. 1985. Strategies for joint ventures. Lexington, MA: Lexington Books.

Kale, P. \& Singh, H. 1999. Building alliance capabilities: A knowledge-based approach. Academy of Management Best Paper Proceedings, Chicago, IL.

Kuhn, T.S. 1977. The essential tension. Chicago, IL: Chicago University Press. 
Lane, P.J. \& Lubatkin, M. 1998. Relative absorptive capacity and interorganizational learning. Strategic Management Journal, 19: 461-477.

Leonard-Barton, D. 1995. Wellsprings of knowledge. Cambridge, MA: Harvard Business School Press.

Mesquita, L.F. 2007. Starting over when the bickering never ends: Rebuilding trust among clustered firms through trust facilitators, Academy of Management Review, 32: 72-91. Mowery, D.C., Oxley, J.E. \& Silverman, B.S. 1996. Strategic alliances and interfirm knowledge transfer. Strategic Management Journal, 17: 77-91, Winter Special issue Mowery, D.C., Oxley, J.E. \& Silverman, B.S. 1998. Technological overlap and interfirm cooperation: Implications for the resource-based view of the firm. Research Policy 27: 507-523. Nelson, R. R.\& Winter, S.G. 1982. An evolutionary theory of economic change. Cambridge, MA: Harvard University Press.

Nohria, N.\& Garcia-Pont, C. 1991. Global strategic linkages and industry structure. Strategic Management Journal, 12: 105-124.

Parkhe, A. 1993. Strategic alliance structuring: A game theoretic and transaction cost examination of interfirm cooperation. Academy of Management Journal, 3: 794-829.

Park, S.H. \& Ungson, G.R. 1997. The effect of national culture, organizational complementarity and economic motivation on joint venture dissolution. Academy of Management Journal, 40: 279-307.

Powell, W.W., Koput, K., \& Smith-Doerr, L. 1996. Interorganizational collaboration and the locus of innovation: Networks of learning in biotechnology. Administrative Science Quarterly, 41: 116145.

Rosenberg, N. 1976. Perspectives on technology, Cambridge (UK), Cambridge University Press. Rosenberg, N. 1996. Uncertainty and technological change. In R. Landau, R. Taylor, G. Wright, eds. The mosaic of economic growth: 334-355. Stanford, CA: Stanford University Press. 
Rosenkopf, L. \& Nerkar, A. 2001. Beyond local search: Boundary-spanning, exploration, and impact in the optical disk industry. Strategic Management Journal, 22: 287-306

Rowley, T., Behrens, D. \& Krackhardt, D. 2000. Redundant governance structures: An analysis of structural and relational embeddedness in the steel and semiconductor industries. Strategic Management Journal, 21: 369-386.

Saxton, T. 1997. The effects of partner and relationship characteristics on alliance outcomes. Academy of Management Journal, 40: 443-461.

Stuart, T.E.\& Podolny, J.M. 1996. Local search and the evolution of technological capabilities. Strategic Management Journal, 17: 21-38

Tushman, M.L. \& O'Reilly, C.A. 1996. Ambidextrous organizations: Managing evolutionary and revolutionary change. California Management Review, 38(4), 8-30.

Uzzi, B. 1997. The social structure and competition in interfirm networks: The paradox of embeddedness. Administrative Science Quarterly, 42: 35-67

Walker, G., Kogut, B. \& Shan, W. 1997. Social capital, structural holes and the formation of an industry network. Organization Science, 8(2): 109-125

Wasserman, S. \& Faust, K. 1994. Social network analysis, methods and applications. Cambridge (UK): Cambridge University Press. 


\section{APPENDIX}

\section{Derivation of Equation (8)}

$\Sigma_{x}^{m A}=\sigma_{x}^{2}\left[\begin{array}{cccc}1 & \rho & \cdot & \rho \\ \rho & 1 & \cdot & \cdot \\ \cdot & \cdot & \cdot & \rho \\ \rho & \cdot & \rho & 1\end{array}\right]=\sigma_{x}^{2} m \rho \overline{J_{m}}+\sigma_{x}^{2}(1-\rho) I_{m}=\sigma_{x}^{2}(1-\rho+m \rho) \overline{J_{m}}+\sigma_{x}^{2}(1-\rho) E_{m}$

where $\overline{J_{m}}=\frac{1}{m} J_{m}$ and $J_{m}$ is an $m$ by $m$ matrix with all elements being equal to 1 . The matrix $E_{m}=I_{m}-\overline{J_{m}}$ where $I_{m}$ is the $m$ by $m$ identity matrix. To derive the posterior variance $\sigma_{m A}^{2}$ we first note that $\overline{J_{m}} \cdot \overline{J_{m}}=\overline{J_{m}}, \overline{J_{m}} \cdot E_{m}=0$, and $E_{m} \cdot E_{m}=E_{m}$. Using a variance decomposition method well known in the analysis of panel data with random effects (Baltagi, 1995: 14) we find that $\left(\Sigma_{x}^{m A}\right)^{-1}=\frac{1}{\sigma_{x}^{2}(1-\rho+m \rho)} \cdot \overline{J_{m}}+\frac{1}{\sigma_{x}^{2}(1-\rho)} \cdot E_{m}$. Therefore, the posterior distribution function $f\left(x_{1}, \ldots, x_{m}, T\right)=f\left(x_{1}, \ldots, x_{m} \mid T\right) \cdot f(T) \propto \exp \left(-\frac{1}{2}(x-\imath T)^{T}\left(\Sigma_{x}^{m A}\right)^{-1}(x-\imath T)\right) \cdot \exp \left(-\frac{1}{2} \frac{(T-\mu)^{2}}{\sigma_{T}^{2}}\right)$ where $\imath$ is an $m$ by 1 vector whose elements contain the number 1 and $x$ is an $m$ by 1 vector containing the observations $x_{i}$. To determine the posterior variance of $T$ it suffices to collect all terms that involve $T^{2}$. These are $\left(\imath^{T}\left(\sum_{x}^{m A}\right)^{-1} \imath+\frac{1}{\sigma_{T}^{2}}\right) T^{2}$. Using the above, $\iota^{T}\left(\overline{J_{m}}\right) l=m$ and $\iota^{T}\left(E_{m}\right) \imath=0$, we find that $\left(\imath^{T}\left(\sum_{x}^{m A}\right)^{-1} \imath+\frac{1}{\sigma_{T}^{2}}\right) T^{2}=\left(\frac{m}{\sigma_{x}^{2}(1-\rho+m \rho)}+\frac{1}{\sigma_{T}^{2}}\right) T^{2}$.

Therefore, the posterior variance of $T$ is equal to $\sigma_{m A}^{2}=\left(\frac{m}{\sigma_{x}^{2}(1-\rho+m \rho)}+\frac{1}{\sigma_{T}^{2}}\right)^{-1}=\left(\frac{m}{\sigma_{x}^{2}(1-\rho)+m \rho \sigma_{x}^{2}}+\frac{1}{\sigma_{T}^{2}}\right)^{-1}$ 


\section{Proof of Proposition}

Since $u$ is implicitly determined by equation (21), we derive the comparative static results as follows. Suppose we want to know the effect of a variable $s$ on $u$. Due to equation (21) it must hold that $\frac{\partial F O C}{\partial u} \cdot \frac{\partial u}{\partial s}+\frac{\partial F O C}{\partial u}=0$. Since $\frac{\partial F O C}{\partial u}=S O C>0, S O C \cdot \frac{\partial u}{\partial s}=-\frac{\partial F O C}{\partial s}$. Hence, the sign of the effect of $s$ on $u$ is the opposite of the sign of the effect of $s$ on FOC. We define $Q=\frac{m}{\sigma_{x}^{2}(1-\rho)+m \rho \sigma_{x}^{2}}$. We first observe that $\frac{\partial F O C}{\partial Q}>0$ and next we find

- $\frac{\partial F O C}{\partial c_{u B \mid m A}^{\prime}}>0$ (straightforward),

- $\frac{\partial F O C}{\partial a}<0$ (straightforward; note that according to equation (5) the parameter $b$ is a function of a),

- $\frac{\partial F O C}{\partial \sigma_{T}^{2}}<0$ (straightforward),

- $\frac{\partial F O C}{\partial \rho}<0 \quad$ (straightforward since $\left.\frac{\partial Q}{\partial \rho}<0\right)$,

- $\frac{\partial F O C}{\partial \sigma_{x}^{2}}<0$ (straightforward since $\frac{\partial Q}{\partial \sigma_{x}^{2}}<0$ ),

- $\frac{\partial F O C}{\partial m}>0$ (straightforward since $\frac{\partial Q}{\partial m} \propto \sigma_{x}^{2}(1-\rho)>0$ ). 
${ }^{1}$ A quadratic cost function could be used as an alternative.

${ }^{2}$ In the next section we present the expression for $\sigma_{n}^{2}$, but not for $\mu_{n}$ since it does not play a role in our analysis.

${ }^{3}$ It can be shown that $(m+1)(1+(m-1) \rho)^{2}-(m-1)(1+m \rho)^{2}=2+2(m-1) \rho-(m-1) \rho^{2}>0$ since $0 \leq \rho<1$ which ensures validity of the inequality sign in equation (16).

${ }^{4}$ The case of the grand design where the firm is confronted with the decision to jointly set up two networks A and B and how to determine the optimal size of each these networks could also be studied using the approach adopted in this paper. Formally this design may be obtained by solving $\min _{m, u}\left(\min _{d} \underset{T, m, u}{E} C(T, d)+c_{m A+u B}\right)$ where $c_{m A+u B}$ denotes the (total) cost of building a network with $m$ alliances of type A firms and $u$ partnerships with type B firms. However, this case is less likely to occur in practice since firms from two different networks are not willing to allow the focal firm to switch between partners from different networks.

${ }^{5}$ The derivation of this equation is a straightforward generalization of the approach we use to obtain equation (8), where to obtain (20) one should replace $\Sigma_{x}^{m A}$ with $\Sigma_{x, y}^{m A+u B}$ in the appendix. Furthermore, it should be noted that the inverse of the matrix $\left(\begin{array}{cc}A & 0 \\ 0 & B\end{array}\right)$ equals $\left(\begin{array}{cc}A^{-1} & 0 \\ 0 & B^{-1}\end{array}\right)$ where the matrices $A$ and $B$ are invertible.

${ }^{6}$ We have also investigated how the optimal number of partners $u$ depends on the parameters $\rho{ }^{*}$ and $\sigma_{y}^{2}$, this does not yield clear conclusions since the corresponding derivatives do not yield unambiguous signs.

${ }^{7}$ Note that the parameter $b$ is a function of the parameter $a$. See also equation (5). 